\title{
ANALISIS KEBUTUHAN SISTEM INFORMASI TERINTEGRASI UNTUK AGRIBISNIS TANAMAN PANGAN
}

\author{
Ayu Kartika Puspa , Ahmad Cucus, Indriati Agustina Gultom, Ahmad Subing \\ Studi Sistem Informasi, Program Studi Informatika, Fakultas Ilmu Komputer \\ Program Studi Manajemen, Fakultas Ekonomi dan Bisnis \\ Universitas Bandar Lampung \\ Lampung Indoensia \\ ayukartikapuspa@ubl.ac.id, cucus@ubl.ac.id, indri.ag@ubl.ac.id, ahmad.subing@ubl.ac.id
}

\begin{abstract}
Economic activities based on food crops and horticulture are very important (strategic) activities in Indonesia. Besides involving the largest labor force in production activities, its products are also a staple food in food consumption in Indonesia. In terms of business, economic activities based on food crops and horticulture are the largest and most widespread business activities in Indonesia. Lampung itself has been known as a national rice barn, but there are still a number of problems, especially related to the availability of fertilizer. This article will discuss the problems that occur in Lampung Province related to food crops, especially rice, ranging from farming plans to marketing and designing integrated information systems to be a solution to these problems.
\end{abstract}

\section{Kata kunci / Keywords: agribusiness, food crops, integrated information systems.}

\begin{abstract}
Abstrak - Kegiatan ekonomi yang berbasis pada tanaman pangan dan hortikultura merupakan kegiatan yang sangat penting (strategis) di Indonesia. Disamping melibatkan tenaga kerja terbesar dalam kegiatan produksi, produknya juga merupakan bahan pangan pokok dalam konsumsi pangan di Indonesia. Dilihat dari sisi bisnis, kegiatan ekonomi yang berbasis tanaman pangan dan hortikultura merupakan kegiatan bisnis terbesar dan tersebar luas di Indonesia. Lampung sendiri telah dikenal sebagai lumbung padi nasional, namun dalam praktik di lapangan masih ditemui sejumlah permasalahan terutama terkait dengan ketersediaan pupuk. Artikel ini akan membahas permasalahan yang terjadi di Provinsi Lampung terkait dengan tanaman pangan khususnya padi, mulai dari rencana usaha tani hingga pemasaran dan perancangan sistem informasi terintegrasi untuk menjadi solusi pada permasalahan tersebut.
\end{abstract}

Kata kunci : agribisnis, tanaman pangan, sistem informasi terintegrasi

\section{Pendahuluan}

Pertanian merupakan sektor yang sangat penting dalam perekonomian nasional sehingga kegiatan agribisnis akan menjadi salah satu kegiatan unggulan Pertanian merupakan sektor yang sangat penting bagi perekonomian nasional, di Indonesia pembangunan ekonomi nasional masih berbasis pertanian secara luas sehingga jasa-jasa dan bisnis yang berbasis pertanian akan semakin meningkat. Kegiatan agribisnis akan menjadi salah satu kegiatan unggulan pembangunan ekonomi nasional dalam berbagai aspek yang luas Kegiatan ekonomi yang berbasis pada tanaman pangan dan hortikultura merupakan kegiatan yang sangat penting (strategis) di Indonesia. Disamping melibatkan tenaga kerja terbesar dalam kegiatan produksi, produknya juga merupakan bahan pangan pokok dalam konsumsi pangan di Indonesia. Dilihat dari sisi bisnis, kegiatan ekonomi yang berbasis tanaman pangan dan hortikultura merupakan kegiatan bisnis terbesar dan tersebar luas di Indonesia. Perannya sebagai penghasil bahan pangan dan pokok, menyebabkan setiap orang dari 200 juta penduduk Indonesia terlibat setiap hari dalam kegiatan ekonomi tanaman pangan dan hortikultura [1].
Komoditas unggulan provinsi lampung adalah kopi dan lada, namun sejak 2019 Provinsi lampung menjadi salah satu dari 8 daerah lumbung padi. Daerah yang diberikan predikat lumbung padi menjadi tumpuan produksi beras nasional. Hal ini menyebabkan pengelolaan tanaman pangan khususnya padi dari hulu ke hilir menjadi perhatian.

Artikel ini akan membahas permasalahan yang terjadi di Provinsi Lampung terkait dengan tanaman pangan khususnya padi, mulai dari rencana usaha tani hingga pemasaran dan perancangan sistem informasi terintegrasi untuk menjadi solusi pada permasalahan tersebut.

\subsection{Permasalahan yang terjadi}

Peneliti melakukan observasi dan wawancara sejak Maret 2019 dengan beberapa sumber yaitu petani pada desa simbar waringin kecamatan Trimurjo Kabupaten Lampung Tengah dan Dinas Ketahanan Pangan, Tanaman Pangan dan Holtikultura Provinsi Lampung. Dari observasi dan wawancara tersebut diperoleh data permasalahan sebagai berikut :

\subsection{Kelangkaan saprotan.}

Dalam kegiatan produksi tani padi, petani memerlukan sarana produksi tani (saprotan) seperti pupuk, benih, 
pestisida dan obat-obatan. Saprotan ini biasanya dibeli pada kios terdekat dengan lokasi pertanian. Pupuk yang digunakan oleh petani dibagi menjadi dua kelompok besar yaitu pupuk subsidi dan pupuk nonsubsidi.

Tabel 1 Perbedaan Jenis Pupuk

\begin{tabular}{|c|c|}
\hline Pupuk Subsidi & $\begin{array}{l}\text { Pupuk subsidi adalah } 5 \text { pupuk } \\
\text { utama yang dapat ditebus } \\
\text { dengan harga murah, Program } \\
\text { pupuk subsidi diadakan oleh } \\
\text { pemerintah dengan jumlah kuota } \\
\text { tertentu setiap tahunnya, yang } \\
\text { berarti tidak semua petani akan } \\
\text { mendapatkan pupuk subsidi. }\end{array}$ \\
\hline & $\begin{array}{l}\text { Beberapa syarat mendapatkan } \\
\text { pupuk subsidiadalah: } \\
\text { 1. Petani tergabung dalam } \\
\text { kelompok tani } \\
\text { 2. Memiliki luas lahan kurang } \\
\text { dari } 2 \text { hektar } \\
\text { 3. Di daftarkan melalui RDKK } \\
\text { (Rencana Definitif } \\
\text { Kebutuhan Kelompok) }\end{array}$ \\
\hline $\begin{array}{ll}\text { Pupuk } & \text { Non- } \\
\text { Subsidi } & \end{array}$ & $\begin{array}{l}\text { Pupuk yang dijual tanpa bantuan } \\
\text { subsidi dari pemerintah. Semua } \\
\text { orang boleh membeli dengan } \\
\text { jumlah yang diinginkan. }\end{array}$ \\
\hline
\end{tabular}

Menurut petani di desa simbar waringin, selama ini pupuk subsidi sulit didapatkan pada musim tanam namun pupuk subsidi tersedia lagi setelah melewati masa tanam. Secara umum pupuk non-subsidi tersedia sepanjang waktu namun banyak petani yang mengandalkan pupuk subsidi sebagai saprotan utama dalam produksi taninya.

a) Perbedaan perlakuan tanaman pangan per wilayah

Dalam produksi tani pembuatan Rencana Usaha Tani (RUT) sangat penting. RUT mencakup kebutuhan saprotan, aksi garap serta jadwal tanam pada masa tanam yang akan berjalan. RUT ini penting untuk dibuat agar kegiatan usaha tani berjalan lancer dan menghasilkan produksi yang optimal, lewat RUT juga dapat dilakukan analisa biaya produksi usaha tani. Peran penyuluh amat penting untuk membantu petani merencanakan kebutuhan produksi taninya. Permasalahan yang ditemui di lapangan adalah RUT yang telah menghasilkan komoditas optimal belum tentu dapat diduplikasi di wilayah lainnya karena perbedaan karakteristik geografis di masingmasing wilayah, sehingga RUT harus dibuat unik dan mengikuti karakter geografis dan lingkungan.

b) Permodalan
Permodalan juga menjadi salah satu permasalahan petani, dijelaskan oleh narasumber bahwa petani biasanya tidak memiliki rekam jejak aliran dana untuk produksi pertanian sehingga tidak dapat diketahui perbandingan modal dengan keuntungan. Sebagian petani menjalankan RUT dengan permodalan dari Kredit Usaha Rakyat bahkan melalui tengkulak, sehingga permodalan dari lembaga keuangan menjadi faktor yang krusial.

c) Pemasaran

Sistem pemasaran di desa simbar waringin dengan cara penjualan kepada pedagang pengumpul atau pengepul, kemudian pengepul menjual ke pedagang besar di Lampung. Hasil produksi padi di desa simbar waringin dijual dalam dua bentuk yaitu dalam bentuk Gabah Kering Basah (GKB) dan Gabah Kering Panen (GKP). Harga GKB lebih rendah daripada GKP. Kecenderungan petani menjual gabah ke pengepul adalah karena lebih efisien dan tidak memakan waktu walaupun harga yang ditawarkan bersifat monopsoni.

\section{Metode}

Penelitian ini bersifat kualitatif karena penelitian ini berangkat dari data, observasi, memanfaatkan teori yang ada sebagai bahan penjelas dan berakhir dengan sebuah teori. Prosedur pelaksanaan penelitian kualitatif bersifat fleksibel sesuai dengan kebutuhan, serta situasi dan kondisi di lapangan Secara garis besar tahapan penelitian jenis kualitatif yang telah dilakukan oleh peneliti adalah: [2]

\subsection{Merumuskan masalah sebagai fokus penelitian.}

Permasalahan yang diangkat oleh peneliti adalah bagaimana mengintegrasikan pihak-pihak yang terkait dalam produksi usaha tani ke dalam satu sistem informasi terintegrasi untuk memenuhi kebutuhan petani.

\subsection{Mengumpulkan data di lapangan}

Tim peneliti lalu memilih satu lokasi penelitian sebagai studi kasus. Tim memilih desa Simbar Waringan kecamatan Trimurjo sebagai lokasi karena daerah ini telah menjadi lokasi demplot oleh salah satu pabrikan pupuk terbesar di Indonesia serta menjadi percontohan tanam benih local. Data dikumpulkan sejak bulan maret 2019 hingga saat ini masih berlangsung.Narasumber pada penelitian ini adalah petani, ketua kelompok tani, penyuluh, Dinas Ketahanan Pangan, Tanaman Pangan dan Holtikultura Provinsi Lampung serta pabrikan pupuk, hal ini dilakukan agar peneliti dapat mengetahui kondisi di lapangan dari berbagai sudut pandang. 


\subsection{Menganalisis data}

Data yang dikumpulkan lalu dikelompokan menjadi daftar permasalahan dan siapa saja pihak-pihak yang terkait dengan pemasalahan tersebut. Tim melakukan diskusi dengan Dinas Ketahanan Pangan, Tanaman Pangan dan Holtikultura Provinsi Lampung serta pabrikan pupuk untuk memperdalam analisis dan merumuskan solusi.

\subsection{Merumuskan hasil studi}

Solusi yang didapat pada proses sebelumnya lalu dijabarkan lebih jauh hingga ke stakeholder atau pihak terkait serta peran dari masing-masing pihak untuk mewujudkan solusi tersebut.

\subsection{Menyusun rekomendasi untuk pembuatan keputusan}

Tim merancang alur data pada sistem informasi terintegrasi agar saling terhubung.

\section{Analisa Proses Bisnis}

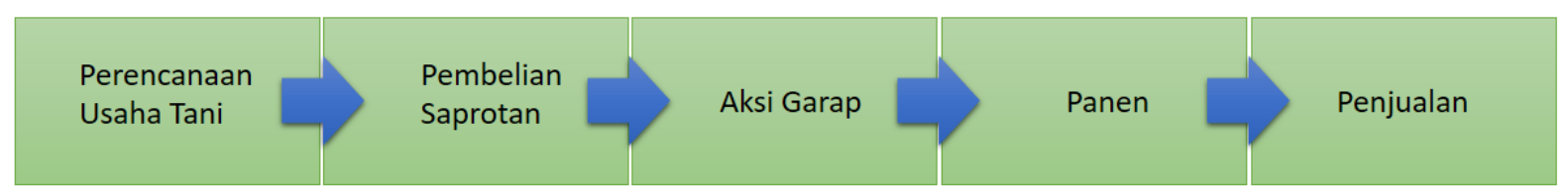

\section{Gambar 1. Analisa Proses Bisnis}

Permasalahan, solusi, serta pihak yang terlibat dijabarkan pada tabel dibawah ini :

Tabel 2 Hasil analisa

\begin{tabular}{|c|c|c|c|c|}
\hline No & Aksi & Permasalahan & Solusi & Pihak yang terlibat \\
\hline 1 & $\begin{array}{l}\text { Perencanaan } \\
\text { Usaha Tani }\end{array}$ & $\begin{array}{l}\text { Petani menduplikasi rencana } \\
\text { usaha tani namun tidak } \\
\text { disesuaikan dengan } \\
\text { karakteristik geografis }\end{array}$ & $\begin{array}{l}\text { Penyuluh dan pakar } \\
\text { pertanian membuatkan } \\
\text { rekomendasi teknologi yang } \\
\text { telah disesuaikan dengan } \\
\text { lokasi dan karakteristik } \\
\text { geografis }\end{array}$ & $\begin{array}{ll}\text { - } & \text { Penyuluh } \\
\text { - } & \text { Pakar } \\
\text { - } & \text { Petani }\end{array}$ \\
\hline 2 & $\begin{array}{l}\text { Pembelian } \\
\text { saprotan }\end{array}$ & $\begin{array}{ll}\text { - } & \text { Kelangkaan dan tidak } \\
\text { tersedianya pupuk pada } \\
\text { saat masa tanam } \\
\text { - } \\
\text { Permodalan }\end{array}$ & $\begin{array}{l}\text { - Kepastian ketersediaan } \\
\text { pupuk dengan cara } \\
\text { mengintegrasikan } \\
\text { kebutuhan pupuk petani } \\
\text { pada RUT langsung ke } \\
\text { pabrikan. Serta } \\
\text { didistribusikan mengacu } \\
\text { pada jadwal tanam di } \\
\text { RUT. } \\
\text { Bekerjasama dengan } \\
\text { Bank Pemerintah untuk } \\
\text { penyaluran KUR dan } \\
\text { kemudahan permodalan } \\
\text { lainnya }\end{array}$ & $\begin{array}{ll}\text { - } & \text { Petani } \\
\text { - } & \text { Pabrikan } \\
\text { - } & \text { Distributor } \\
\text { - } & \text { Kios } \\
\text { - } & \text { Bank }\end{array}$ \\
\hline 3 & Aksi Garap & Kebutuhan air irigasi & $\begin{array}{ll}\text { Integrasi jadwal tanam } \\
\text { dan garap pada RUT } \\
\text { dengan dinas terkait }\end{array}$ & $\begin{array}{ll}- & \text { Petani } \\
- & \text { Dinas } \\
& \text { Pengairan dan } \\
& \text { Pemukiman } \\
& \text { Provinsi } \\
& \text { Lampung } \\
\text { - } & \text { Pemerintah } \\
& \text { Daerah } \\
\end{array}$ \\
\hline 4 & Panen & - & - & - \\
\hline 5 & Penjualan & $\begin{array}{l}\text { Penjualan dengan harga } \\
\text { monopsony }\end{array}$ & Membuka pasar lebih luas & $\begin{array}{ll}\text { - } & \text { Petani } \\
\text { - } & \text { Pembeli } \\
\end{array}$ \\
\hline
\end{tabular}




\subsection{Perancangan sistem informasi terintegrasi}

Dari permasalahan dan solusi yang telah dianalisis, tim membuat rancangan alur data dan informasi untuk sistem informasi terpadu pertanian sebagai berikut :

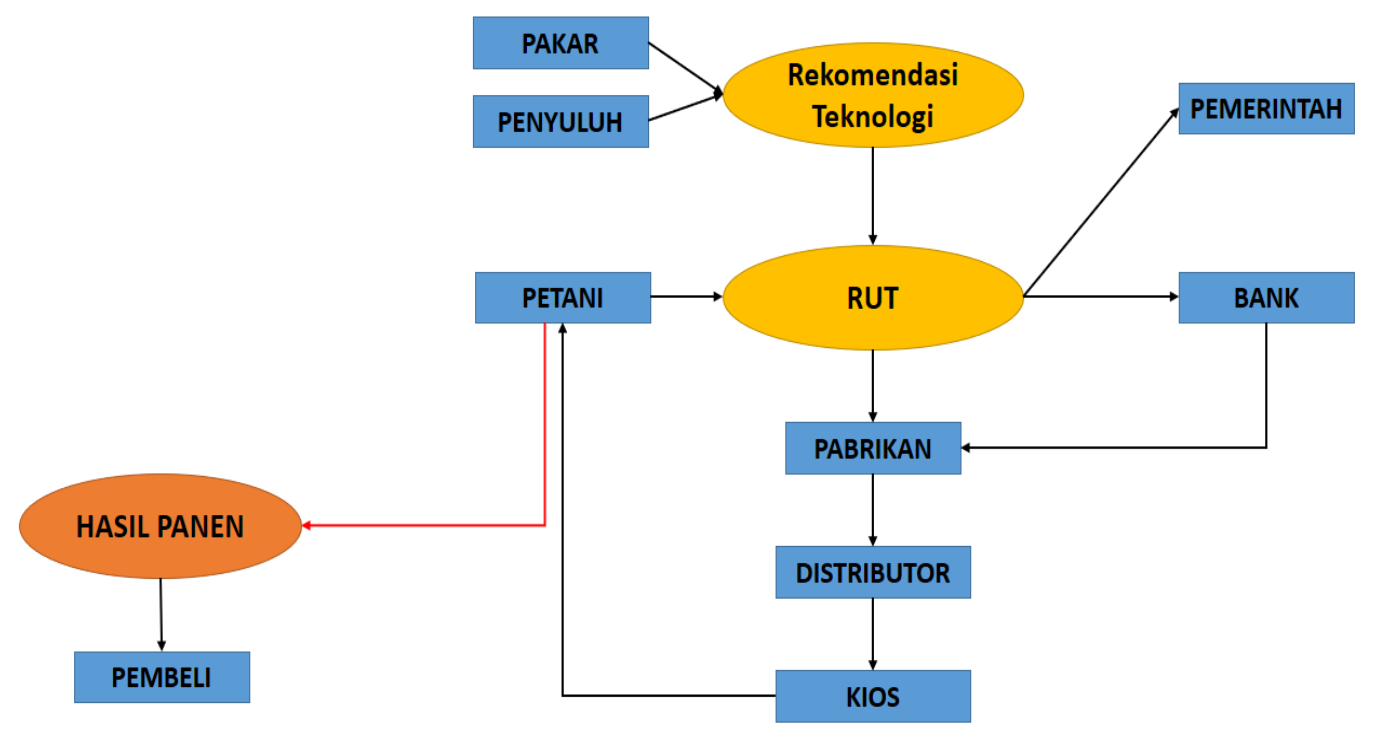

Gambar 2. Perancangan sistem informasi terintegrasi

Dalam perancangan sistem informasi terintegrasi ini stakeholder dibagi kedalam beberapa langkah.

a) Langkah pertama adalah pembuatan rekomendasi teknologi, langkah ini adalah solusi bagi permasalahan rencana usaha tani. Pada langkah ini penyuluh dan pakar pertanian memiliki akun tersendiri dimana peran penyuluh dan pakar sebagai pemberi rekomendasi teknologi untuk hasil komoditas yang optimal sesuai dengan karakteristik geografis.

b) Langkah kedua adalah RUT, hasil rekomendasi teknologi oleh penyuluh dan pakar lalu dikemas sebagai Rencana Usaha Tani (RUT) untuk acuan produksi pertanian oleh petani. RUT ini mencakup kebutuhan saprotan, jadwal tanam, kebutuhan biaya serta aksi garap yang harus dilakukan.

c) Langkah ketiga adalah integrasi data ke pihak terkait. Data RUT pada langkah sebelumnya didistribusikan ke pihakpihak yang terkait untuk ditindaklanjuti dalam rangka pemenuhan kebutuhan petani. Pihak pertama yang terlibat adalah Bank untuk permodalan berdasarkan kebutuhan biaya pada RUT. Pihak kedua adalah pemerintah dalam hal ini adalah Dinas Pengairan dan Pemukinan Provinisi Lampung yang akan mengatur aliran air irigasi sesuai dengan jadwal tanam. Pihak ketiga adalah pabrikan, data yang didapat oleh pabrikan adalah kebutuhan saprotan pada RUT petani.

d) Langkah keempat adalah pendistribusian saprotan. Untuk memastikan ketersediaan pupuk maka data RUT yang digunakan sebagai acuan idealnya didistribusikan setidaknya 14 hari dari masa tanam, bank akan melakukan transaksi pembayaran berdasarkan permodalan yang diajukan pada RUT untuk menghindari keterlambatan pembayaran. Lalu pabrikan akan mengirimkan saprotan sesuai dengan pesanan ke distributor hingga kios terdekat dengan petani.

e) Langkah kelima adalah pasca panen. Sistem informasi ini akan menyediakan pasar terbuka untuk pemasaran komoditas, tujuannya agar pembeli dan petani dapat saling terhubung serta mendapatkan harga terbaik untuk kedua belah pihak.

\section{Daftar Pustaka}

[1] R. Juarsyah, A.Muani and A. Suyatno 'Kajian Pengembangan Agribisnis Komoditas Unggulan BuahBuahan di Kabupaten Kubu Raya", Jurnal Social Economic of Agriculture, vol 4. no. 1, pp 56-69

[2] Sugiyono, "Memahami Penelitian Kualitatif", CV. Alfabeta Bandung, 2005 